\title{
REFLEXÕES SOBRE O CONCEITO DE MÍSTICA NO MONAQUISMO CRISTÃO
}

\author{
REFLECTIONS ON THE CONCEPT OF THE \\ MYSTIC CHRISTIAN MONASTICISM
}

JoRge GABRIEL ROdRIGUeS De OLIVEIRA ${ }^{(*)}$

\begin{abstract}
Resumo
Recentemente, o Bispo Emérito de Roma, Papa Bento XVI, em sua Exortação Apostólica, mostrou interesse e preocupação com a questão da leitura da Sagrada Escritura e consequentemente com a Lectio Divina na Igreja. Sendo assim, nos propomos a analisar o conceito de mística na prática espiritual monástica. Será abordada a questão da mística monástica cristã, em três níveis: o conceito de mística em seu âmbito geral e mais especificamente dentro do Cristianismo, determinando suas peculiaridades; buscaremos identificar, não a gênese da mística cristã, mas suas possíveis raízes em dois grandes movimentos influenciadores do Cristianismo no Ocidente, quais sejam, a Filosofia grega e o Gnosticismo oriental. Por fim, analisaremos o espiritualismo e a mística próprias do monaquismo cristão.
\end{abstract}

Palavras-Chave: Cristianismo. Mística. Monaquismo.

\begin{abstract}
Recently, the Bishop Emeritus of Rome, Pope Benedict XVI in his Apostolic Exhortation, showed interest and concern with the issue of reading of Sacred Scripture, and hence with Lectio Divina in the Church. Therefore, we propose to examine the concept of monastic mysticism in spiritual practice. Will address the issue of Christian monastic mysticism, on three levels: the concept of mysticism in its general scope and more specifically within Christianity, determining their peculiarities; seek to identify, not the genesis of Christian mysticism, but its possible roots in two major movements influencers of Christianity in the West, namely, the eastern Greek philosophy and Gnosticism. Finally, we analyze spiritualism and mysticism own Christian monasticism.
\end{abstract}

KEYWORDS: Christianity. Mystique. Monasticism.

\section{Mística Sobrenatural E SAGRAda}

Em 30 de Setembro de 2010 foi promulgada a Exortação Apostólica Pós-Sinodal Verbum Domini pelo então Sumo Pontífice Bento XVI, na qual Vossa Santidade dirigindo-se ao Episcopado, ao Clero, às pessoas consagradas e aos fiéis leigos, tratou sobre a Palavra de Deus na vida e na missão da Igreja. Dividido em três partes, quais sejam: Verbum Dei, Verbum Ecclesia e Verbum Mundo, o documento, dentre outros pontos, retoma a discussão e mostra a importância da prática da Lectio

\footnotetext{
${ }^{(*)}$ Especialista Lato Sensu em História Antiga e Medieval - Religião e Cultura, pela Faculdade de São Bento do Rio de Janeiro, Professor de História da Secretaria de Estado de Educação do Rio de Janeiro. E-mail: profjgabrielhistoria@gmail.com
} 
Divina para que a Igreja (instituição e seus membros) possa reavivar seu espiritualismo, fundamentando suas ações em Cristo, ou seja, no Verbo Encarnado, pois acretida que dessa maneira existe a possibilidade de alcançar a unidade entre o quadrinômio: fiel Igreja - Cristo - Deus, como segue:

$\mathrm{Na}$ certeza de que a Igreja tem o seu fundamento em Cristo, Verbo de Deus feito carne, o Sínodo quis sublinhar a centralidade dos estudos bíblicos no diálogo ecuménico, que visa a plena expressão da unidade de todos os crentes em Cristo. De facto, na própria Escritura, encontramos a comovente súplica de Jesus ao Pai pelos seus discípulos para que sejam um só a fim de que o mundo creia ( Jo 17,21). Tudo isto nos fortalece na convicção de que escutar e meditar juntos as Escrituras nos faz viver uma comunhão real, embora ainda não plena; pois «a escuta comum das Escrituras impele ao diálogo da caridade e faz crescer o da verdade». (VERBUM DOMINI, 2010, p. 81, grifo nosso).

Práticas místicas, enquanto fenômeno religioso, ocorrem em diversas religiões (GRÜN, 2012, p.25-26) e remontam épocas tão distantes que antecedem até mesmo o surgimento do Cristianismo. Essas experiências, podem ser encontradas em religiões próximo-orientais (CARDOSO, 1990, p.11), em tribos totêmicas americanas e australianas (Durkheim, 2000, p. 241) ou até mesmo na Grécia Antiga, através dos cultos de mistérios (VERnANT, 2009, p. 69). Entretanto, cabe ressaltar que não pretende-se estabelecer uma espécie de elo entre os modelos místicos diversos e o modelo monástico cristão, nem mesmo tentar construir uma linha evolutiva da mística, considerando que "El monacato cristiano no es hijo ni de las formas ascéticas del hinduismo o del budismo, ni de las comunidades pitagóricas, ni de cualquier otra manifestación pareja" (ColOMBÁs, 1998, p.18). Porém, consideramos questões como apropriações culturais (CHARTIER, 1990, p. 17), principalmente no que se refere à aspectos conceituais, religiosos e discursivos para a formação da mística monástica cristã, uma vez que:

El hecho de no deber su existencia ni su inspiración esencial a influencias extrañas al cristianismo no significa, con todo, que el monacato primitivo se viera completamente libre de impactos e infiltraciones procedentes de tradiciones filosóficas y corrientes espirituales del 'mundo exterior'. (COLOMBÁs, 1998, p. 20).

Nas religiões, desde as mais simples praticadas ainda anteriormente à invenção da escrita, até as mais complexas ou institucionalizadas, como o Catolicismo, por exemplo, uma característica pode ser considerada imperativa, qual seja: a existência de fenômenos sobrenaturais, quase como a base fundamental de sua 
existência. Sendo assim, tanto em tribos totêmicas quanto nas catedrais medievais, os seres humanos tentavam dominar, controlar, explicar ou mesmo se entregar a esses fenômenos que escapavam a sua compreensão, conforme afirma Durkheim:

Uma noção que geralmente é considerada como característica de tudo aquilo que é religioso é a de sobrenatural. Com esse termo entende-se toda uma ordem de coisas que vai além do alcance de nosso entendimento; o sobrenatural é o mundo do mistério, do incognoscível, do incompreensível. (DURKHEIM, 2000, p. 54).

Contudo, apesar de os seres humanos não conseguirem explicar seus mecanismos e às vezes nem ao menos exprimir com palavras como se dá a ocorrência desses fenômenos entendidos como extranaturais, não podemos afirmar que estes ocorrem de forma completamente desconexa do natural ou da realidade inteligível pelo homem. Pois, para que se tenha a noção da existência de fenômenos misteriosos, ou seja, inexplicáveis, é necessário antes possuir a noção contrária, portanto, de todos os fenômenos considerados naturais, não misteriosos ou explicáveis através da consciência e/ou razão humana.

Em outras palavras, o sobrenatural depende do natural, o mistério depende do que está à mostra, o inexplicável depende do explicável. Portanto, podemos dizer que "[...] o sobrenatural absolutamente não se reduz ao imprevisto. O novo, assim como seu contrário, faz parte da natureza" (Durkheim, p. 58). Porém, independentemente dos fenômenos sobrenaturais possuírem ou não uma dependência dos naturais, os primeiros continuam carentes de uma explicação cabal, ou de fato, plenamente inteligíveis pela consciência racional humana; neste ponto é que as religiões exercem o seu papel fundamental, de lidar com o extranatural, constituindo-o como seu próprio objeto.

Já que os homens encontraram nas religiões uma maneira de tratar do sobrenatural, como pode uma manifestação tão abstrata a ponto de não poder ser explicada, apenas sentida, ou seja, apreendida pelos órgãos dos sentidos humanos, ser reconhecida como tal? Isto ocorre pelo seu caráter sagrado e sua relação com as coisas de caráter profano. Ou seja, para que o homem reconheça tais fenômenos misteriosos, estes devem manifestar-se de tal modo que o homem os veja ou os sinta de alguma outra maneira que seu corpo físico permita. Contudo, quando estes fenômenos sobrenaturais, reconhecidos como sagrados, se manifestam para o homem, ou nele próprio, o que temos é uma hierofania do sagrado. 
O homem toma conhecimento do sagrado porque este se manifesta, se mostra como algo absolutamente diferente do profano. A fim de indicarmos o ato da manifestação do sagrado, propusemos o termo hierofania. Este termo é cômodo, pois não implica nenhuma precisão suplementar: exprime apenas o que está implicado no seu conteúdo etimológico, a saber, que algo de sagrado se nos revela. [...]Encontramonos diante do mesmo ato misterioso: a manifestação de algo 'de ordem diferente' de uma realidade que não pertence ao nosso mundo - em objetos que fazem parte integrante do nosso mundo 'natural', 'profano'. (ELIADE, 1992, p. 13).

Partindo dessas premissas, podemos dizer então que mediante toda a guisa de fenômenos sobrenaturais ou sagrados que pululam nas religiões, a experiência mística torna-se um de seus elementos constitutivos. Esta afirmação explica-se porque este tipo de experiência é um fenômeno transcendente - portanto sobrenatural, inexplicável, sagrado e hierofânico - uma vez que "qualquer descrição, especialmente racional, seria inadequada na transmissão do conteúdo da experiência mística, que se assemelharia mais a estados de sentimento do que de intelecto" (SHOJI, 2003, p. 55).

Podemos considerar a mística como um tipo de experiênca transcendental, por extrapolar o âmbito do natural; e religiosa, por seu caráter sagrado e hierofânico de se manisfestar no homem ou para o homem. Ou seja, nestes termos entendemos que esse tipo de experiência "parece designar normalmente uma transgressão dos limites da razão, desenrolando-se num plano transracional” (VAZ, 1992, p. 494), ou ainda como uma "experiência que tem lugar num plano transracional onde cessa o discurso da razão fazendo com que a inteligência e o amor possam convergir numa experiência inefável [...] que arrasta toda a energia pulsional da alma" (VAZ apud OLIVEIRA, 2003, p. 129).

Esses pressupostos permitem uma aproximação da "fenomenologia" da experiência mística, entretanto, em que bases conceituais, de fato, se constitui a mística enquanto fenômeno religioso? Para dar conta de responder este questionamento, tornar-se-á imperativa a noção dos fundamentos antropológicos ${ }^{1}$ desse tipo de experiência. Contudo, consideramos que para apreender esses fenômenos, a ponto de conceituá-los, na impossibilidade de reproduzi-los, é importante tomar como principal fonte de dados os relatos dos próprios místicos, pois estes, por terem vivenciado as experiências, são os únicos capazes de teorizá-

\footnotetext{
${ }^{1}$ A utilização do termo "fundamentos antropológicos" não significa a intenção de analisar diretamente o objeto de estudo pelo viés desta ciência, mas foi tomada como base a mesma nomenclatura utilizada por Henrique C. De Lima Vaz, em obra de referência anteriormente citada.
} 
las de fato, conforme nos recomenda Lima Vaz (1992, p. 495). Sendo assim, uma aproximação conceitual da mística seria:

Várias dessas experiências nos ensinam que se trata de um encontro com o Outro Absoluto, diante do qual acontece a experiência do Sagrado. Em outras palavras, há uma anulação da distância entre o sujeito e o objeto. O que acontece é uma união, ou quase-identidade, com o Absoluto: uma experiência fruitiva e participativa do Absoluto, uma espécie de mergulho no Ser do Absoluto. Em outras palavras, é uma suprassunção (Aufhebung) do corpo e do psiquismo para o nível do espírito. (OLIVEIRA, 2003, p. 129).

Tomando como base esta conceituação, podemos afirmar então que a experiência mística é um fenômeno de união entre os opostos interdependentes: o natural e o sobrenatural, nas palavras de Durkheim, ou o sagrado e o profano, nas de Eliade. Porém, entendemos que o nível em que se dá a união mística entre esses pólos - o homem e o Absoluto - é o externo, o da suprassunção, ao passo que para alcançar esse nível, torna-se necessário, primeiramente, que ocorra a união mística em nível interno, da infrassunção, ou seja, no próprio ser.

É isto que o autor quer dizer com o princípio do Aufhebung; a saber, o significado latino da palavra "revogar", revoco ou revocare, que suscitam a ideia de recuperar, restabelecer, recordar, mas também de anular ou de tirar o efeito, fazer com que algo deixe de vigorar. Se adaptarmos essa etimologia à realidade estudada, o resultado que temos é a noção primeva de união entre o sagrado e profano, natural e sobrenatural. Em outros termos, do ser que recupera, restabelece e recorda a sua essência no Absoluto, mas também do ser que anula, tira os efeitos do corpo sobre o espírito, faz com que o corpo do místico deixe de vigorar sobre sua alma.

Em síntese, "A experiência mística apresenta-se, no entanto, dentro da esfera do Sagrado, caracterizada pela anulação da distância imposta entre sujeito e objeto pela manifestação do Outro absoluto como tremendum" (VAZ, 1992, p. 496.), isto é, o Absoluto como incrível, como extraordinário. Sendo assim, chegamos ao ponto fortuito em que torna-se necessário uma aproximação mais cuidadosa em relação aos dois agentes da mística em seu âmbito interno ou da infra-assunção, o corpo e a alma.

Schmitt já sublinhou em seu verbete que as relações que se estabelecem entre o corpo e a alma não são de caráter universal e muito menos imutável, portanto, ao 
longo da História e em cada civilização, é correto afirmar que a noção desses dois elementos sofrem distinções (LE GofF; SchmitT, 2002, p. 253). Ainda segundo o autor, cabe ressaltar que na relação entre corpo e alma para a tradição ocidental, e portanto cristã, o que se tem é uma inferência profícua que remonta desde o paganismo greco-romano à uma herança veterotestamentária, que se fundiram a partir da pregação paulina.

Se a filosofia greco-romana, em seus diferentes componentes, legou à Idade Média uma terminologia de categorias que permite pensar a relação entre alma e corpo, a tradição judaico-cristã permitiu inscrever essa relação em seu grande mito universal do devir da humanidade, do Gênesis à ressurreção dos mortos e ao Juízo Final, passando pela paixão de Cristo, que chancela seu sentido cristão. (LE GoFF; SHIMITT p. 254).

Doravante, para a concepção cristã, podemos afirmar que "cada homem se compõe tanto de um corpo, material, criado e mortal, quanto de uma alma, imaterial, criada e imortal" (LE GofF; ShimitT, p.255). Ou seja, o próprio homem composto de parte natural/profana (o corpo) e sobrenatural/sagrada (a alma) parece representar, em si, uma espécie de microcosmo do fenômeno religioso. É neste ponto que a relação entre corpo e alma encontra-se com a experiência mística, pois podemos identificar no fenômeno da supra-assunção dois tipos de experiência que são decorrentes de determinadas práticas que envolvem a relação corpo-alma, qual sejam: o êntase e o êxtase. No primeiro caso, "o Absoluto é experimentado como constituindo o fundo abissal, o interior íntimo do próprio sujeito" e no segundo caso "o Absoluto é experimentado como Absoluto pessoal e manifesta-se como dom de si, introduzindo o místico na comunhão da vida divina" (Oliveira, 2003, p. 129) .

Não podemos deixar de mencionar que, para a concepção cristã, a relação entre corpo e alma assumiu um caráter conflituoso, que acabou levando a noção de desprezo ao corpo e a supervalorização da alma, considerando que "o corpo é desprezado, condenado, humilhado. A Salvação, na cristandade, passa por uma penitência corporal. [...] O papa Gregório, o Grande, qualifica o corpo de 'abominável vestimenta da alma'. [...] O monge mortifica seu corpo." (LE GofF; TRUONG, 2006, p. 11). 
Essa "grande renúncia" 2 ao corpo, torna-se manifestada no ideal ascético, que é introduzido a partir da Patrística e do surgimento do monaquismo, pois ambos possuíam grande influência na Igreja durante a Antiguidade Tardia, tanto que a vida monástica tornou-se o modelo ideal de vida cristã (LE GoFF; TRUONG, 2006, p. p. 37). Porém, o que ocorreu de fato foi mais impactante do que a renúncia e o desprezo do corpo, uma vez que "a oposição do corpo e da alma remete ao antagonismo homólogo de dois princípios criadores do bem (Deus) e do mal (Satã)" (LE GofF; SchmitT, 2002, p. 257). Contudo, tornar-se-á preciso se aproximar com mais cuidado acerca da ideia de ascetismo, pois essa prática não foi criação original do Cristianismo, nem tampoco do monaquismo, pois remonta épocas ainda mais distanciadas desses movimentos.

\section{Mística FilosófiCA, GNÓSTICA E ANGELOMÓRFICA}

Le Goff e Truong afirmam que as raízes da repressão ao corpo e por conseguinte a gênese das práticas ascéticas no âmbito do Cristianismo encontramse na Antiguidade Tardia, mas que, ao que parece, o ocorrido na Spätantike 3 possui raízes ainda mais profundas, levando em consideração que "a 'renúncia da carne', se produziu, de início, sob o Império Romano, no interior daquilo que se chamou paganismo" (Le GofF; Truong, 2006., p. 47). Os autores ainda se utilizam das ideias desenvolvidas por Paul Vayne ${ }^{4}$, quando concordam que o âmago dessa questão refere-se ao estoicismo praticado pelo imperador Marco Aurélio, portanto no século II, entre os anos 180 e 200; a saber, anteriormente ao período tardoantigo.

Sendo assim, concordamos quando enfatizam que o Cristianismo não foi $o$ responsável pela repressão ao corpo ou mesmo pela criação das práticas ascéticas,

\footnotetext{
${ }^{2}$ A expressão está sendo utilizada em referência direta a subseção homônima do capítulo intitulado "Quaresma e Carnaval: uma dinâmica do Ocidente" (p. 33-88) encontrado na obra "Uma História do Corpo na Idade Média”, já devidamente citada.

3 O termo refere-se a Antiguidade Tardia, que segundo a Historiografia é um período limítrofe entre a Antiguidade e o Medievo, tradicionalmente situado entre os anos 200 e 700 de nossa Era: "I wish to trace in the late second, third, and early fourth centuries the emergence of features that were far from clearly discernible at the time when our Christian brothers entered the cave and which finally came together to form the definitively Late Antique style of religious, cultural, and social life that emerged in the late fourth and early fifth centuries." (BROWN, 1993, p. 1, grifo nosso).

4 Conforme indicado pelos autores, vide: VEYNE, Paul. La Famille et L'amour Sous le Haut Empire Romain. In: Annales E.S.C., 1978.
} 
pois quando surgiu e mesmo durante seu desenvolvimento "a coisa já estava feita", parafraseando os autores. Doravante, cabe ressaltar que "A Idade Média dará um impulso muito mais forte a essa depreciação corporal e sexual por meio de seus ideólogos, na seqüência de Jerônimo e Agostinho, [...] assim como por seus praticantes, os monges" (LE GOFF; TRUONG, 2006, p. 49).

Torna-se então necessário, para compreender melhor essas ideias ascéticas de renúncia ao corpo, imbricadas entre o paganismo romano, de influência grega e o Cristianismo, com sua carga oriental, seguirmos o mesmo caminho trilhado por Jaeger, quando tratou do "Cristianismo e da sua relação com a cultura grega [...]" (1993, p.13). Porém, não queremos dizer, com isso, que o Cristianismo foi apenas fruto de uma espécie de simbiose entre conceitos gregos e práticas judaicas, mas sim afirmar a existência de certo grau de influência que a civilização grega relegou à religião cristã ocidental, partindo do pressuposto que:

[...] este processo da cristianização do mundo de língua grega dentro do Império Romano não foi de forma alguma unilateral, pois significou ao mesmo tempo a helenização da religião cristã. [...] Com a língua grega, todo um mundo de conceitos, categorias de pensamento, metáforas herdadas e subtis conotações de sentido entra no pensamento cristão. (JAEGER, p. 16-17).

Porém, não pretendemos apenas repetir as soluções já engendradas por Jaeger, que dão conta de elucidar todo o arcabouço conceitual inerente a cultura grega que serviu de fundamento para a chamada "Paideia de Cristo", mas sim identificar, em linhas gerais, de onde pode ter vindo a influência grega para a religião cristã, apenas no que se refere à prática do ascetismo, enquanto método para vivenciar uma experiência mística de união com o sagrado, sobrenatural, absoluto, conforme anteriormente analisado.

O fio condutor que permitiu essas interações culturais foi o Hellenismos, que em seu sentido original remonta a difusão do uso correto da língua grega. Posteriormente passou a representar "a adoção das maneiras gregas, do modo de vida grego, em especial fora da Hélade, onde a cultura grega torna-se moda". Numa análise mais recente, podemos considerar, portanto, o "helenismo" como um universo de cultura prioritariamente grega que se difundiu nos períodos helenístico e romano e, em menor grau, no bizantino; e por conseguinte, a "helenização" como 
“o processo de adoção e adaptação desta cultura [grega] em um nível local”. (CheVitarese; Cornelli, 2003, p. 07).

Este processo permitiu, com certa facilidade, que ocorressem as apropriações culturais, uma vez que o Cristianismo, em seus primeiros momentos, era um movimento judaico, mas aqueles judeus já consideravam-se helenizados, tanto na Diáspora, quanto na própria Palestina e também nos tempos da pregação paulina. A saber, foi justamente para essa parcela de judeus helenizados que evangelizadores cristãos atuaram, quando "após o martírio do seu mentor Estêvão, se espalhou por toda a Palestina e iniciou as actividades missionárias da geração seguinte" (JAEGER, 1993, p. 18).

$\mathrm{Na}$ prática, as apropriações culturais que ocorriam entre o helenismo e o cristianismo, podem ser encontradas nos autores cristãos do período apostólico, pois estes utilizavam a mesma formatação literária dos gregos, como por exemplo a Epístola, seguindo o mesmo modelo utilizado pelos filósofos gregos. Esse processo foi ainda muito mais amplo e multifacetado, partindo da premissa que diversas formas filosófico-literárias gregas foram sendo, cada vez mais, apropriadas pelos escritores cristãos, que as revestiam de novas representações, como a "Diatribe e Dialexis da filosofia popular grega, que tentava levar os ensinamentos dos Cínicos, Estóicos e Epicuristas ao povo" (JAEGER, 1993, p. 20).

Deixando a Palestina de cultura judaica para tomar a rota do mundo greco-romano, a missão é levada a se encontrar com outras crenças, outras expressões da religiosidade e outras instituições, envolvendo a fé, diferentes daquelas do judaísmo. Apresenta-se, então, aos missionários um desafio: encontrar as expressões adequadas para expressar a própria mensagem. (PRIETO, 2007, p. 46).

Ora! Aqui nos deparamos, outra vez, com o estoicismo praticado pelo imperador Marco Aurélio, como mencionado anteriormente. Mesma corrente filosófica que, segundo Le Goff e Truong, foi a grande responsável pela noção da "recusa da carne", posteriormente desenvolvida na Antiguidade Tardia. Portanto, apenas com o objetivo de ilustrar as linhas gerais do pensamento aqui desenvolvido, e não com a finalidade de analisar pausadamente as diversas correntes filosóficas gregas, até mesmo pelo fato dessa atitude fugir dos nossos objetivos, identificamos em algumas dessas correntes, fundamentos pontuais da mística em voga, como mostrado na tabela 1 : 
Tabela 1

\begin{tabular}{|l|l|}
\hline \multicolumn{1}{|c|}{ Filósofos: } & \multicolumn{1}{c|}{ Argumentos místicos: } \\
\hline $\begin{array}{l}\text { Pitágoras (século VI } \\
\text { a.E.C.) }\end{array}$ & $\begin{array}{l}\text { Transmigração da alma, identificação com o divino, } \\
\text { contemplação. }\end{array}$ \\
\hline Heráclito (540-480 a.E.C.) & Unidade, princípio do Absoluto. \\
\hline $\begin{array}{l}\text { Anaxágoras (século V } \\
\text { a.E.C.) }\end{array}$ & Unidade, origem única. \\
\hline Platão (428-347 a.E.C.) & $\begin{array}{l}\text { Fuga do mundo prático, contemplação, desprezo ao } \\
\text { corpo. }\end{array}$ \\
\hline \multicolumn{1}{|c|}{ Correntes filosóficas: } & \multicolumn{1}{c|}{ Argumentos místicos: } \\
\hline Cinismo e Ceticismo & Fuga do mundo social, afasia, ataraxia da alma. \\
\hline Epicurismo & Ataraxia da alma. \\
\hline Estoicismo & Unidade, apatia. \\
\hline Neoplatonismo & $\begin{array}{l}\text { Princípio do Absoluto, Uno transcendente, mistério, } \\
\text { hierofania, contemplação. }\end{array}$ \\
\hline
\end{tabular}

Fonte dos dados: ABRÃO, Bernadette Siqueira (Org.).

A História da Filosofia. São Paulo: Nova Cultural, 2004. p. 27-91.

Como uma das muitas resultantes desse processo de apropriações de conceitos gregos pelo cristianismo, podemos dizer que a própria figura do filósofo, ou seja, o praticante da filosofia, que a grosso modo podemos entender como o "amor ao conhecimento" (ABRÃO, 2004, p. 5), também foi apropriada. Porém, foi revestida de uma nova representação: a do teólogo; esta figura que se distinguia do crente cristão comum, pelo fato de conhecer o verdadeiro sentido dos livros sagrados. Sendo assim, a partir do século II a tendência de transcender filosoficamente, portanto com carga do que se entendia como verdade, as mensagens contidas nas Escrituras, deu conta do aparecimento de sistemas chamados gnósticos, uma vez que "Gnosis é o termo elegante para esta tendência de transcender a esfera da pistis [...]". (JAEGER, 1993, p.76). .

Podemos então entender o gnosticismo nascente na segunda centúria de nossa Era, como um "conjunto dos sincretismos desse gênero [filosofia grega] que, encontrando então a nova fé cristã [oriental], tentaram assimilá-la” (GILSON, 2001, p. 25). Entretanto, cabe ressaltar que, devido as circunstâncias, o movimento gnóstico não se apresentou de maneira homogênea. Isto é, podemos afirmar que coexistiram diversos gnosticismos (Couliano; EliAdE, 1993, p. 90). Mas, entretanto, 
em todas essas doutrinas podem ser encontradas determinadas características fundamentais que nos permitem classificá-las genericamente de gnósticas.

Doravante, se tomarmos como base a conceituação de mística já abordada, que refere-se a elementos tais quais o sobrenatural, sagrado, Absoluto e a possibilidade de união transcendental entre os homens e esta instância extranatural, através da supra-assunção e da infra-assunção da alma, o que temos são confluências bem claras desses elementos místicos com a prática da gnose. Em outras palavras, a gnose ao pregar a existência de mensagens que transcendem ao registrado de fato nas Escrituras, acaba afirmando que algumas pessoas, capazes de alcançar tal verdade, conseguem estabelecer uma espécie de contato com o que chamamos até aqui de Absoluto, pelo fato de serem capazes de compreendê-lo plenamente, em seu mais profundo significado. Por isso, podemos dizer ser a gnose uma "forma particular de conhecimento místico" (ANTISERI; REALE, 2003, p. 34):

O século II depois de Cristo é uma época de ativa fermentação religiosa. De todas as partes e sob todas as formas, procura-se e crê-se encontrar os meios para alcançar a desejada união da alma com Deus. Saber se Deus existe e o que se pode afirmar razoavelmente a seu respeito, em suma conhecê-lo como filósofo, não parece mais suficiente; o que se busca é uma gnose (gnôsis), isto é, uma experiência unificadora e divinizadora que permita alcançá-lo num contato pessoal e unir-se realmente a ele.

O que podemos destacar do movimento gnóstico, na prática, a título de exemplo, foi a atuação de um dos seus grandes precursores, a saber: Fílon de Alexandria. O que este judeu helenizado fez, foi tentar interpretar o texto veterotestamentário, tomando como base algumas categorias conceituais elaboradas pela filosofia grega. Isto é, para elaborar sua alegoria gnóstica, se apropriou do conceito de logos, desenvolvido no estoicismo; da estrutura do mundo suprassensível do platonismo; conferindo-lhes novas representações ao relacioná-los com representações éticas, antropológicas e teológicas do Antigo Testamento. Ao elaborar tais teorias, conhecidas esquematicamente como "filosofia mosaica”. Fílon também aproxima-se da nossa conceituação de mística, conforme síntese representada na Tabela 2: 


\section{Tabela 2}

\begin{tabular}{|c|l|}
\hline \multicolumn{2}{|c|}{ Elementos místicos na antropologia de Fílon de Alexandria: } \\
\hline \multirow{3}{*}{ Constituição humana } & Corpo: físico, natural. \\
\cline { 2 - 2 } & Alma-intelecto: terrena, corruptível. \\
\cline { 2 - 2 } & Espírito: sobrenatural, divino. \\
\hline \multirow{2}{*}{$\begin{array}{c}\text { Dimensões da vida } \\
\text { humana }\end{array}$} & Física: puramente animal (corpo). \\
\cline { 2 - 2 } & Racional:mediadora (alma-intelecto). \\
\cline { 2 - 2 } & Superior: transcendente (espírito). \\
\hline
\end{tabular}

Fonte dos dados: ANTISERI, Dario; REALE, Giovanni. História da Filosofia: Patrística e Escolástica, Tradução Ivo Stomiolo. São Paulo: Paulus, 2003. p. 33. V. 2.

Sendo assim, não é um equívoco dizer que Fílon, através de sua alegoria gnóstica, serviu como uma "liga" entre as representações gregas e judaicas no cristianismo nascente. Entretanto, além do uso do texto veterotestamentário, portanto canônico, identificamos outros elementos da cultura oriental, isto é, judaica, que também foram apropriados nesse momento, contudo, considerados pela tradição bíblica como extracanônicos.

Originalmente, o Cristianismo era um produto da vida religiosa do Judaísmo. Descobertas recentes, como a dos chamados manuscritos do Mar Morto, lançam nova luz sobre este período da religião judaica e foram traçados paralelos entre a piedade ascética da seita religiosa, que vivia então nas margens do Mar Morto, e a mensagem messiânica de Jesus. (JAEGER, 1993, p. 15, grifo nosso).

Sob as luzes do conceito de mística e das interações culturais que ocorreram entre o cristianismo e o judaismo, um dos elementos que podem ser destacados, além da tradição veterotestamentária de Fílon, é o angelomorfismo desenvolvido em Qumran. De acordo com este conceito, existe a possibilidade dos seres humanos transcenderem sua natureza carnal, ou seja, sua condição física propriamente humana, alcançando uma condição "santificada"5, supra-humana, ou em outras palavras, assumir forma angelical ${ }^{6}$, através de rígidas práticas ascéticas. É neste sentido que Fletcher-Louis considera o angelomorfismo como "a dimensão

5 A expressão foi utilizada em devido alinhamento com as ideias desenvolvidas em: MACHADO, Jonas. O Mito de Moisés Divino Entronizado nos Céus: Leituras Míticas da Figura de Moisés na Literatura Judaica e sua Recepção nas Origens do Cristianismo. Orácula, São Bernardo do Campo, v. 1, n. 2, 2005, p. 27-40.

${ }^{6} \mathrm{Um}$ dos indícios que nos conduziu até a questão do angelomorfismo, foi a utilização da expressão vita angelica ou "vida angélica" para definir a vida monástica, como pode ser observado em ampla literatura sobre o tema do monaquismo. Apenas para ilustrar, vide: MORESCHINI, Claudio; NORELLI, Enrico. História da Literatua Cristã Antiga, Grega e Latina. São Paulo: Edições Loyola, 200o, p. 190. 
transcendente e espiritual da criação [...] ainda que sempre subordinada ao único Deus [...]. A afirmação de que homens transformados são anjos/deuses implica em divindade derivada do próprio Deus criador." (MACHADO, 2005, p. 29).

Em suma, sobre a piedade ascética praticada na seita de Qumran, cabe ressaltar que "it is widely supposed that human life and religious practice was thought at this time to mirror on earth the activity of the angels in heaven" (FLETCHER-LOUIS, 2000, p. 292). Com isso, podemos dizer que os membros daquela comunidade aproximavam-se da experiência mística, se for levada em consideração as questões relativas a transcendência do corpo físico, em direção a Engelgemeinschaft, conforme os termos do autor.

\section{MísTiCA MonÁSTICA}

Para darmos conta de tratarmos da mística no âmbito do monaquismo, tornarse-á necessário elucidarmos questões que dizem respeito a sua própria historicidade. De maneira esquemática, iremos tratar este tema a partir de sua frente oriental. Isto é, buscaremos identificar na história monástica desenvolvida, primeiramente, no Oriente, as suas próprias representações da mística enquanto prática religiosa no âmbito do Cristianismo.

Mas, nesse contexto, que é o monge? A pergunta é básica, no entanto muito necessária, pois torna-se difícil desvencilhar as práticas, dos papéis sociais que as representam. Ou seja, se estamos buscando, em última instâcia, abordar a mística experimentada pelos monges, orientais e ocidentais, necessitamos a priori, decifrar quem são, ou quem foram. Para isto, é preciso caracterizá-los primeiro de uma maneira lato e ulteriormente, adaptarmos a caracterização aos ambientes supracitados. Sendo assim, analisemos o conceito de monge a seguir:

Monge/monja - Religioso de tipo anacoreta, mas que no Ocidente, vivendo em comunidade, está ligado a uma ordem monástica que siga a Regra de S. Bento ou outra no quadro dum mosteiro (Monaquismo), e, por isso, anterior às ordens mendicantes (século XIII). (DIAS, 2005, p. 202).

Tal definição de monge, talvez pelo fato de ter sido fomentada por um membro da Ordem de São Bento, cria um vínculo direto entre a figura do monge ocidental e a Regra proposta pelo santo e também não explica as suas origens. Isto torna-se um problema para as nossas análises, uma vez que se seguirmos tal glossário, estaremos 
limitando a noção de monge no Oriente apenas a "religiosos anacoretas", para fidelizarmos as palavras do autor.

Entretanto, Dom García Colombás, também OSB, já constroi um conceito bem mais alargado e permeado de detalhes, no qual podemos nos basear para entender a figura do monge. Para o autor, os verdadeiros monges surgiram na Antiguidade e "movidos por el Espíritu, se internaban en la hosca soledad del desierto [...] y en el retiro de un cenobio con el único objeto de agradar a Dios, buscarle y gozar, por la oración y el contacto con los libros sagrados." (COLOMBÁs, 1998, p. 3). Essa definição parece delimitar eficazmente o conceito de monge, uma vez que estabelece um vínculo com outras abordagens e até mesmo perfaz o caráter etimológico do termo, como segue:

Referimo-nos aos primeiros monges que, segundo a própria terminologia etimologia de seu nome, em grego, monachós - aquele que vive na solidão - estabelecer-se-iam em lugares ermos em busca das mortificações à vontade do mundo e a só contemplação da presença de Deus, não obstante, buscando ainda um enfrentamento mais direto e íntimo com o diabo e assim o prêmio de sua salvação. (AMARAL, 2008, p. 121).

Nas definições que se apresentam, podemos observar alguns elementos comuns e outros singulares. Como elementos comuns identificamos: a vida solitária e a busca/contemplação de Deus. Como elementos singulares identificamos: o cenobio (mosteiro), a prática da oración, a leitura dos libros sagrados, a mortificação7, a luta contra o diabo e a própria salvação. Doravante, a partir desses dois campos de observação, podemos agora estabelecer o que é o monge: eram pessoas que optavam por um vida solitária, com objetivo de buscar a contemplação de Deus. Poderiam viver isolados ou em mosteiros. Praticavam tanto a oração, baseada na leitura dos Sagradas Escrituras, quanto a mortificação, com objetivo de lutar contra as tentações e com isto conseguir a salvação de sua alma.

Noutras palavras e de acordo com o dito por Daniel-Rops, o monge é, em sentido strictu, "um homem que se retirou do mundo, onde julga não poder encontrar a paz do coração e os meios de salvação” (AMARAL, 20o8, p. 216). A saber, dentre essas características gerais, podemos encontrar aproximações claras quanto a prática da experiência mística, quais sejam: a busca e a contemplação de Deus e a

\footnotetext{
7 "Mortificação - Privação ou sacrifício voluntário para lutar contra as tentações e apurar o autodomínio. Faz parte da ascese religiosa.” (DIAS, 2005, p. 202).
} 
mortificação enquanto prática ascética.

Á guisa de organização, primeiramente analisaremos a tradição mística dos primeiros monges, os orientais. Entretanto, isto não significa dizer que elementos que foram próprios daquelas representações à leste do mapa, também não venham fazer parte da ramificação ocidental do monaquismo. Porém, ressaltamos aqui a singularidade de alguns conceitos, levando em conta sua historicidade; portanto, a época em que foram elaborados e desenvolvidos e também seu locus próprio: o deserto; uma vez que para o Ocidente, além do monaquismo ter se desenvolvido mais tardiamente que no Oriente, então, noutro contexto temporal, também ocorreu num cenário diferenciado, a floresta e a montanha. Estes fatores, por si só, já justificam a necessidade de análises pontuais.

De acordo com a tradição monástica ${ }^{8}$ oriental, a origem dos elementos que compõem esse ideal de vida, está contida nos Atos dos Apóstolos, portanto, são conceitos que tornaram-se "as linhas mestras do Monaquismo: compunção, obediência, oração comum, pobreza etc” (MoRIN, 2002, p.8). Por conseguinte, sendo o ideal monástico dos primeiros dias uma tentativa de reprodução do modo de vida dos Apóstolos, portanto, as pessoas que conviveram com maior proximidade de Cristo e seguiam seus ensinamentos, podemos concordar com Morin, quando este afirma que, em suma, a vida monástica é a vida cristã elevada ao grau de perfeição.

Apenas a título de ilustrar melhor essa definição de ideal de vida monástica, enquanto a elevação da vida cristã à condição de perfeição, podemos fazer uma breve comparação desta ao conceito grego de arete $^{9}$, levando em conta que podemos aproximar esse conceito à palavra "virtude" em nosso idioma. Nestes termos, o ideal monástico seria então a elevação da vida cristã elevada a sua máxima virtude, qual seja, a vida apostólica.

Retomando os quatro elementos constitutivos da tradição monástica dos primeiros tempos - portanto oriental - de acordo com as afirmações elaboradas

\footnotetext{
${ }^{8}$ Neste contexto, quando nos utilizamos do termo "tradição monástica", não desejamos dar conta de todos os seus atributos conceituais, mas sim focarmos a análise em apenas um dos elementos dessa tradição: a mística. 9 "O tema essencial da história da formação grega é antes o conceito de arete, que remonta aos tempos mais antigos. Não temos na língua portuguesa um equivalente exato para este termo; mas a palavra 'virtude', na sua acepção não atenuada pelo uso puramente moral, e como expressão do mais alto ideal cavaleiresco unido a uma conduta cortês e distinta e ao heroísmo guerreiro, talvez pudesse exprimir o sentido da palavra grega." (JEAGER, 1995, p. 25).
} 
por Morin, quais sejam: compunção, obediência, oração comum e pobreza; devemos agora investigá-los de uma forma mais aproximada e cuidadosa, com o objetivo de verificar se em todos esse elementos, ou ao menos em alguns deles, conseguimos identificar certo grau de teor místico, a saber, a transcendência do corpo físico para a contemplação ou união momentanea com Deus, através da observação de práticas ascéticas ou de autodomínio.

Para a análise acima, vide a Tabela 3, a seguir:

\section{Tabela 3}

\begin{tabular}{|l|l|}
\hline \multicolumn{1}{|c|}{$\begin{array}{c}\text { Elementos } \\
\text { monásticos: }\end{array}$} & \multicolumn{1}{|c|}{ Argumentos místicos: } \\
\hline Compunção & $\begin{array}{l}\text { Despertar da alma, causado por angústia da consciência, } \\
\text { em decorrência da vida em pecado. }\end{array}$ \\
\hline Obediência & $\begin{array}{l}\text { Disposição a total entrega para cessar as angústias e } \\
\text { recondução das vontades, faculdades e atos em direção a } \\
\text { Deus. }\end{array}$ \\
\hline Oração & $\begin{array}{l}\text { Litúrgica: Ofício Divino, coletivo, que conduz à } \\
\text { contemplação. } \\
\text { Individual: amplia a contemplação através do silêncio e } \\
\text { meditação. }\end{array}$ \\
\hline Pobreza & $\begin{array}{l}\text { Abandono do mundo materialista, que conduz a prática da } \\
\text { caridade através da partilha dos bens estritamente } \\
\text { necessários. }\end{array}$ \\
\hline
\end{tabular}

Fonte dos dados: MORIN, D. Germain, OSB. O Ideal Monástico e a Vida Cristã dos Primeiros Dias. Tradução de D. Estêvão Bettencourt OSB. Juiz de Fora: Mosteiro da Santa Cruz, 2002, p. 16-133.

De acordo com o analisado na Tabela 3, podemos observar que nos quatro elementos da tradição monástica destacados, existem argumentos de caráter místico. Contudo, consideramos que a obediência e a pobreza encontram-se num nível não-transcendental, uma vez que o primeiro diz respeito a comportamentos e atitudes e o segundo a condição material. Portanto, são elementos que servem apenas para conduzir o monge ao nível transcendental da experiência mística, com efeito, propriamente dita. Entretanto, os outros elementos, compunção e oração, estes sim estão no nível da transcendência. Uma vez que o primeiro ocorre nas instâncias mental e espiritual (consciência e alma) e o segundo eleva o praticante à theorein. Isto é, à contemplação, que segundo os gregos, era sempre estar na presença de Deus, para vê-lo. Porém, "Não olham para Deus diretamente, mas, na 
beleza da criação e na imagem do homem, eles obtêm uma noção da absoluta beleza de Deus" (GRÜN, 2012, p. 32).

Sobre a compunção, tornar-se-á necessária uma análise imediata. Com efeito, Morin, primeiramente, compara a compunção com uma "espada do Espírito", capaz de "penetrar até o íntimo da alma espiritual" (2002, p. 20). Essa "espada" é, noutros termos, a própria Palavra de Deus, pois "é viva e eficaz, mais aguçada que uma espada de dois gumes; penetra até a juntura da alma e do espírito" (Idem). Por esta razão, a compunção é capaz de despertar a alma e causar angústia mental, quando o monge passa a perceber sua antiga vida no mundo, permeada pelo pecado. A compunção então pode ser compreendida como uma espécie e autoanálise de consciência, que visa, em última instância, o arrependimento e o encontro do praticante com sua própria essência mais profunda, conforme demonstrado no Diagrama 1, a seguir:

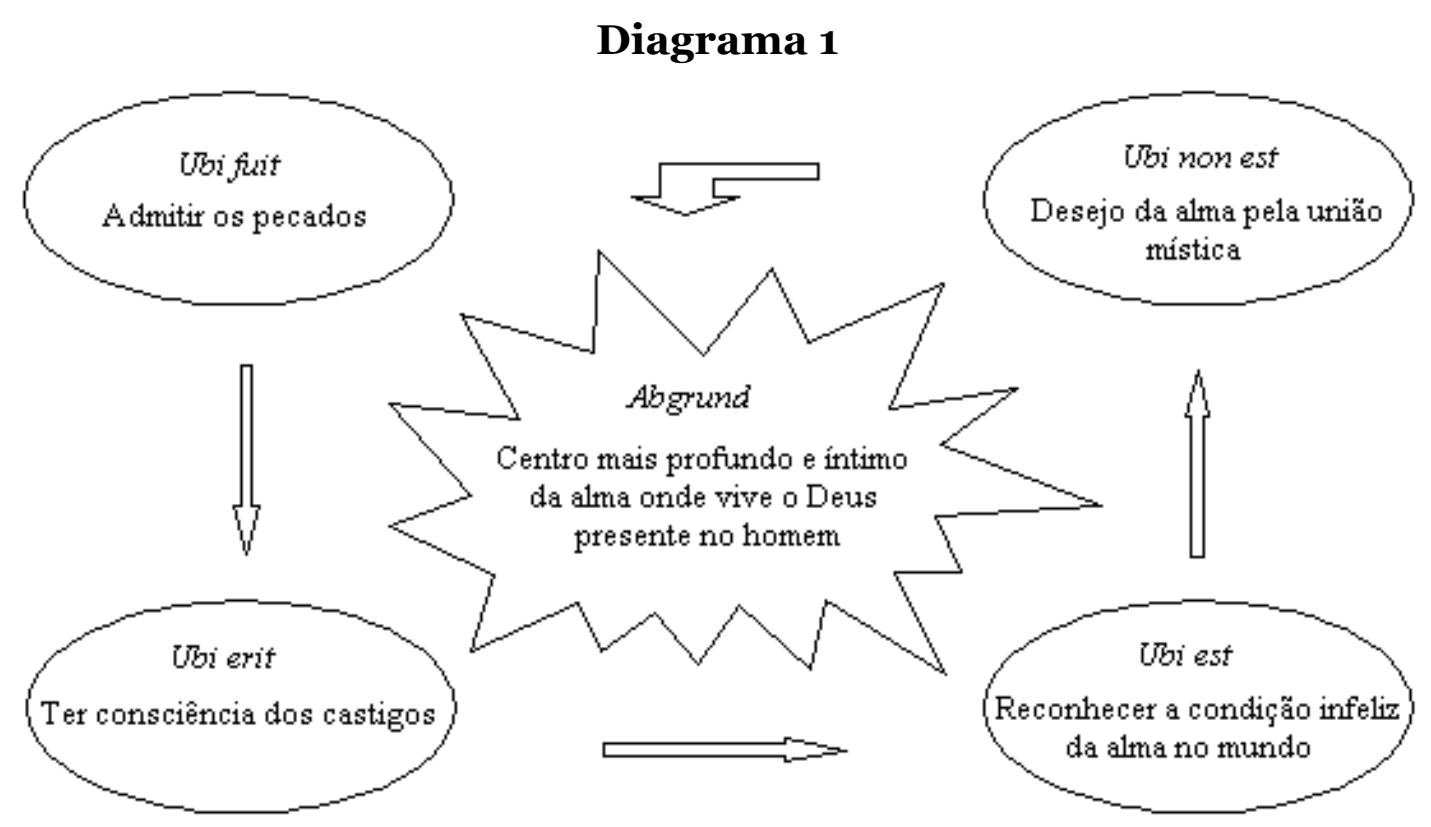

No que se refere ao Diagrama $1^{10}$, Morin cria uma comparação, afirmando que os quatro elementos constituintes da compunção (Ubi fuit, Ubit erit, Ubi est, Ubi non

${ }^{10}$ Fonte dos dados: “Abgrund”: BARSOTTI, Divo. Monaquismo e Mística. Tradução Mosteiro da Santa Cruz. Juiz de Fora: Ed. Subiaco, 2009, p. 11-12. / "Ubi fuit, Ubit erit, Ubi est, Ubi non est": MORIN, D. Germain, OSB. O Ideal Monástico e a Vida Cristã dos Primeiros Dias. Tradução D. Estêvão Bettencourt OSB. Juiz de Fora: Mosteiro da Santa Cruz, 2002, p. 22-25. 
est)"11, são como "flechas agudas capazes de abater a seus pés [de Deus] povos inteiros" (2002, p. 21). Ainda explica que todas as quatro foram forjadas sob o temor e sob o amor, valendo ressaltar que nas duas primeiras, Ubi fuit e Ubi erit, a predominância é do temor, ao passo que nas duas últimas, Ubi est e Ubi non est, o que predomina é o amor; e a título de complementação, utilizamos o conceito de Abgrund, o abismo, o âmago do ser, onde é possível encontrar Deus, fomentado por Barsotti. Com efeito, exatamente neste ponto, podemos traçar uma ligação entre a tradição monástica oriental, dos primeiros tempos, e a ocidental, a posteriori; através dos dois conceitos germânicos, o Aufhebung (já analisado) e o Abgrund.

Em suma, consideramos que a tradição mística do Oriente, portanto em sua gênese, "recorre prevalentemente, à teologia do Antigo Testamento" (BARSOTTI, 2009, p. 13), apesar das influências helenistas observadas entre os judeus helenizados e, em certa medida, até no movimento gnóstico. Essa mística, preconizava uma verdadeira transformação da natureza humana. Portanto, "na espiritualidade oriental o termo último da vida do espírito era a 'Theosis', a divinização do homem” (2009, p. 70). Porém, cabe ressaltar que "a mais íntima união da natureza humana com a natureza divina não eliminou a natureza humana, mas, antes, a potencializou em sua distinção da divindade" (2009, p. 41).

\section{REFERENNCIAS}

ABRÃO, Bernadette Siqueira (Org.). A História da Filosofia. São Paulo: Nova Cultural, 2004.

AMARAL, Ronaldo. Os Monges e a Cristianização do Campo na Antiguidade Tardia Hispânica. A Leitura e a Propagação de um Mundo Escatológico a partir do Texto Bíblico. SÆCULUM - Revista de História, 18, João Pessoa, Jan/Jun., 20o8, p. 121-127.

ANTISERI, Dario; REALE, Giovanni. História da Filosofia: Patrística e Escolástica, V. 2. Tradução de Ivo Stomiolo. São Paulo: Paulus, 2003.

BARSOTTI, Divo. Monaquismo e Mística. Tradução Mosteiro da Santa Cruz. Juiz de Fora: Ed. Subiaco, 2009

BROWN, Peter. The Making of the Late Antiquity. Estados Unidos, Massachusetts: Harvard University Press, 1993.

${ }^{11} \mathrm{O}$ conteúdo do Diagrama 1, em referência aos quatro elementos da compunção, é fruto de nossas análises, numa tentativa de sintetizar as explicações do autor; entretanto, para maior esclarecimento, segue a tradução dos termos em latim encontradas no livro: Ubi fuit: onde esteve; Ubi erit: onde estará; Ubi est: onde está; Ubi non est: onde não está (MORIN, 2002, p.22-25). 
CARDOSO, Ciro Flamarion. Antiguidade Oriental: Política e Religião. São Paulo: Contexto, 1990.

CHARTIER, Roger. A História Cultural: Entre Práticas e Representações. Tradução de Maria

Manuela Galhardo. Rio de Janeiro: Bertrand Brasil, 1990.

CHEVITARESE, André Leonardo; CORNELLI, Gabrielli. Judaismo, Cristianismo, Helenismo:Ensaios sobre Interações Culturais no Mediterrâneo Antigo. São Paulo, Itu: Ottoni Editora,2003.

COLOMBÁS, Dom Garcia M., OSB. El Monacato Primitivo. 2. ed. Madri: Biblioteca de Autores Cristianos, 1998.

DIAS, Geraldo J. A. Coelho, OSB. Glossário Monástico-Beneditino: Em Torno dos Espaços Religiosos - Monásticos e Eclesiásticos. Portugal, Porto: IHM-UP, 2005.

DURKHEIM, Émile. As Formas Elementares da Vida Religiosa: O Sistema Totêmico na Austrália. Tradução Paulo Neves. São Paulo: Martins Fontes, 2000.

ELIADE, Mircea. O Sagrado e o Profano. Tradução de Rogério Fernandes. São Paulo: Martins Fontes, 1992.

COULIANO, Ioan P. Dicionário das Religiões. Tradução de Pedro Moreira Araújo. Protugal, Lisboa: Publicações Dom Quixote, 2003.

FLETCHER-LOUIS, Crispin H. T. Some Reflections on Angelomorphic Humanity Texts Among the Dead Sea Scrolls. Dead Sea Discoveries, 7, 3, 2000, p. 292-312.

GILSON, Etienne. A Filosofia na Idade Média. Tradução de Eduardo Brandão. SãoPaulo: Martins Fontes, 2001.

GRÜN, Anselm, OSB. Mística: Descobrir o Espaço Interior. Tradução de Luiz de Lucca. Petrópolis: Vozes, 2012.

JAEGER, Werner. Cristianismo Primitivo y Paideia Griega. $6^{\text {a }}$ Reimpressão, México: Fondo de Cultura Económica, 1993.

Paidéia: A Formação do Homem Grego. Tradução de Artur M. Parreira. São Paulo: Martins Fontes, 1995.

LE GOFF, Jacques; SCHMITT, Jean-Claude (Orgs.). Dicionário Temático do Ocidente Medieval. Bauru, SP: EDUSC; São Paulo, SP: Imprensa Oficial do Estado, 2002.

. TRUONG, Nicolas. Uma História do Corpo na Idade Média. Rio de Janeiro: Civilização Brasileira, 2006. 
MACHADO, Jonas. O Mito de Moisés Divino Entronizado nos Céus: Leituras Míticas da Figura de Moisés na Literatura Judaica e sua Recepção nas Origens do Cristianismo.

Orácula, São Bernardo do Campo, v. 1, n. 2, 2005, p. 27-40.

MORESCHINI, Claudio; NORELLI, Enrico. História da Literatua Cristã Antiga, Grega e Latina. São Paulo: Edições Loyola, 2000, p. 190.

MORIN, D. Germain, OSB. O Ideal Monástico e a Vida Cristã dos Primeiros Dias. Tradução deD. Estêvão Bettencourt OSB. Juiz de Fora: Mosteiro da Santa Cruz, 2002.

OLIVEIRA, Ednílson Turozi de. Recensão: Henrique C. de Lima Vaz, Experiência Mística e Filosofia na Tradição Ocidental. Numen: revista de estudos e pesquisas da religião, Juiz de Fora, v. 6, n, 2, p. 127-139.

PRIETO, Christine. Cristianismo e Paganismo: A Pregação do Evangelho no Mundo Greco-Romano. São Paulo: Paulus, 2007.

SHOJI, Rafael. Condições de Significado na Linguagem Mística. Revista de Estudos da Religião n. 4, 2003 , p. 54-73.

VAZ, Henrique C. de Lima. Mística e Política: A Experiência Mística na Tradição Ocidental. Síntese Nova Fase, v. 19, n. 59, 1992.

VERNANT, Jean-Pierre. Mito e Religião na Grécia Antiga. Tradução de Joana Angélica D’Ávila Melo. São Paulo: Martins Fontes, 2009.

VEYNE, Paul. La Famille et L'amour Sous le Haut Empire Romain. In: Annales E.S.C., 1978. 